\title{
Payments for physician services: an analysis of Maryland Medicaid reimbursement rates
}

\author{
S. Hamid Fakhraei \\ Center for Health Program Development and Management, \\ University of Maryland, Baltimore County, 1000 Hilltop Circle, \\ Baltimore, MD 21250, USA \\ E-mail: fakhraei@chpdm.umbc.edu
}

\begin{abstract}
This paper describes the process of increasing reimbursement rates for physicians who provide services to Maryland Medicaid enrollees. It compares Maryland Medicaid reimbursement rates for physicians with Medicare fees in Maryland and Medicaid reimbursement rates of other states. It also provides an analysis of the impact of the increases in reimbursement rates on the participation of physicians in the Medicaid programme. Based on the analysis presented in this article, which targets the increase in reimbursement rates to evaluation and management procedures, the Maryland Government increased physician fees in the Medicaid programme beginning July 2002. Evaluation and management procedures are usually office visits provided by either a primary care physician or a specialist.
\end{abstract}

Keywords: medicaid; physician fees; reimbursement rates.

Reference to this paper should be made as follows: Fakhraei, S.H. (2006) 'Payments for physician services: an analysis of Maryland Medicaid reimbursement rates', Int. J. Healthcare Technology and Management, Vol. 7, Nos. 1/2, pp.129-142.

Biographical notes: S. Hamid Fakhraei, a Doctor of Economics, is the Director of Economic Analyses at the Center for Health Program Development and Management, University of Maryland, Baltimore County. He has extensive experience in healthcare finance and payment methodologies.

\section{Introduction}

In recent years, the Maryland Medicaid programme has undergone significant expansion. Medicaid enrollment of children has grown by over 150,000 since 1998, primarily due to the implementation of the Maryland Children's Health Program (MCHP). The demographics of this newly eligible population have resulted in an increase in the need for primary care physicians, especially pediatricians and family practitioners. The rise in the total Medicaid population has increased the number of Medicaid patients within each physician's practice. As a result, the share of Medicaid revenues and their importance to the viability of participating physicians' practices has increased.

The Maryland Medicaid Advisory Committee and policymakers had raised concerns about the low level of reimbursement rates for physicians who provide services to Maryland's Medicaid programme. In addition, there have been concerns about the impact 
of reimbursement on access to care for Medicaid enrollees to physicians' services. This issue affects the Maryland Medicaid managed care programme, known as HealthChoice as well, because the payment rates for physicians of most managed care organisations (MCOs) to physicians are tied to the Medicaid fee-for-service fee schedule.

Prior to July 2002, the fees paid to physicians had not increased in Maryland for over a decade, while reimbursement rates for most other Medicaid-covered services had increased. The majority of Maryland Medicaid expenditures are for components of healthcare (inpatient and outpatient hospital, nursing home, pharmacy, etc.) and their reimbursement rates increase regularly. For example, Maryland's Health Services Cost Review Commission (HSCRC) considers inflation in its annual review of hospital rates. ${ }^{1}$ Nursing home rates are also automatically adjusted annually in accordance with the state law to reflect increasing costs. The greatest component of prescription drug costs, ingredient fees, has increased as the costs of inputs rise. Fees for other providers, including Federally Qualified Health Centres, Home Health Agencies and Medical Day Care Providers are also adjusted annually.

During the 2000 and 2001 sessions, Maryland's legislature considered a range of options for addressing Medicaid reimbursement rates in an effort to ensure provider participation in the programme. The resulting legislation required a study to recommend a methodology for increasing reimbursement rates for providers. Based on the results of the study, upon which this article is based, despite budget shortfalls, the governor and the legislature appropriated an additional $\$ 50$ million total funds ( $\$ 25$ million state funds) to increase physician fees in the Medicaid programme for the fiscal year beginning July 2002.

The remainder of this article is organised into five sections. Section 2 is an analysis of the participation of physicians in the Medicaid programme. Section 3 provides an analysis of Maryland Medicaid the reimbursement rates of physicians. Section 4 reviews adjustments to reimbursement rates for services provided by physicians and analyses Maryland Medicaid fees and physician participation after the rate increase. Section 5 discusses future rate increases. Section 6 provides a conclusion.

\section{Participation of physicians in the Medicaid programme}

It was a requirement of the Federal law that the Medicaid programmes of a state ensures that 'payments are sufficient to enlist enough providers so that care and services are available under the plan at least to the extent that such services are available to the general population in the geographic area' ${ }^{2}$

Various researchers who studied the participation of physicians in the Medicaid programme have arrived at the following findings (Tucker III, 2002):

- a positive association exists between Medicaid reimbursement rates and physician participation in the Medicaid programme. Increase in Medicaid fees could result in full participation of those physicians who partially participate in the Medicaid programme (Tucker III, 2002; Adams, 1995; 2001; Baker and Royalty, 2000)

- as the number of physicians per population increases, which in turn leads to increased competition among physicians, an increase in Medicaid fees would have a more pronounced effect on physician participation 
- $\quad$ as the practice cost of the physicians increases, their participation in the Medicaid programme decreases. This negative association between costs and participation in the Medicaid programme is stronger for primary care physicians than for specialists

- a lower-than-average percentage of board-certified primary care physicians participate in the Medicaid programme

- a higher-than-average percentage of foreign medical graduates participate in the Medicaid programme.

In assessing the adequacy of the access of Medicaid enrollees to healthcare services, an evaluation and comparison of physicians per 100,000 populations was carried out. Maryland ranks fourth in the nation, with an average of 382 physicians per 100,000 populations, compared to the national average of 268 per 100,000 populations (Kaiser Family Foundation, 2003). It has been suggested that in areas with high physician-to-population ratios, the competition among physicians for patients would lead to greater access for Medicaid beneficiaries, because increased competition leads to a decrease in revenue from private patients (Tucker III, 2002).

In addition, research based on national data has shown that a higher percentage of physicians accept Medicaid patients in states with relatively high reimbursement levels. A recent study based on a year 2000 national survey of pediatricians concludes that there is a strong relationship between Medicaid participation and level of payments (Berman et al., 2002). An evaluation of two measures of the participation of primary care pediatricians in the Medicaid programme was made in this study. The first measure, 'full participation', refers to the proportion of private office based primary care pediatricians who accept all Medicaid patients that request care. The second measure, 'relative participation', refers to the ratio of pediatricians who accept all Medicaid patients versus those who accept all non-Medicaid patients. A ratio of one indicates equal access by Medicaid and non-Medicaid patients. A ratio of less than one suggests lower access by Medicaid patients. The 'relative participation' measure is the more robust one, in that it accounts for pediatricians who are at full capacity and do not accept new patients. Table 1 compares these two access measures for Maryland and nearby states.

Table 1 Measures of participation of pediatricians in Medicaid programmes

\begin{tabular}{lccccccc}
\hline Description & $D C$ & $V A$ & $P A$ & $D E$ & $W . V A$ & $M D$ & National Average \\
\hline $\begin{array}{l}\text { Full participation } \\
\text { percentage }\end{array}$ & 60.0 & 55.6 & 57.6 & 51.9 & 69.6 & 65.0 & 54.6 \\
Relative participation & 0.86 & 0.78 & 0.72 & 1.08 & 0.91 & 0.81 & 0.77 \\
\hline
\end{tabular}

The 'full participation' measure in Table 1 indicates that Maryland is only second to West Virginia in the region. On the other hand, the 'relative participation' data show that the access of Medicaid enrollees to pediatricians before the July 2002 fee increase was higher in Delaware, West Virginia, and Washington, DC than in Maryland. This can be attributed to higher reimbursement rates in Delaware and West Virginia, and higher physicians per population ratio in Washington, DC. However, Pennsylvania and Virginia Medicaid enrollees have relatively lower access than Maryland. Both measures indicate that the access of Maryland Medicaid enrollees to pediatricians is higher than the national average. 


\section{Analysis of Maryland medicaid physician reimbursement rates}

\subsection{Comparisons with Medicare fees}

The methodology adopted by Medicare to pay physicians was used to allocate the new funds and to determine the new Medicaid physician fee schedule. Medicare fees are based on the Resource Based Relative Value Scale (RBRVS). This methodology relates payments to the resources and skills that physicians use to provide a service. Three categories of resources determine the Relative Value Unit (RVU) of each procedure: physician work, practice expense, and malpractice expense. A geographic cost index and a conversion factor are used to convert RVUs to fees. Medicare fees are adjusted annually for inflation. Several factors are used to derive annual adjustments for Medicare fees, including changes in medical costs, Medicare enrollment, and gross domestic product per capita. As a result, Medicare fees may increase or decrease in any given year according to the annual adjustment. ${ }^{3}$ In addition, Medicare fees are adjusted depending on where a procedure is performed. Medicare fees for some procedures are lower if they are performed in hospitals or require skilled nursing facilities rather than in offices or other places.

A comparison was made between the Maryland Medicaid payment rates and the average payments made by the Medicare programme in Maryland. Currently, there are about 7,300 procedure codes in the Maryland Medicaid claims and MCO encounter data. About 6,500 or $89 \%$ of these procedures match with the Medicare fee schedule. These procedures account for about $89 \%$ of total payments, including estimated MCO payments. The Medicare fees for about 900 of the matched procedure codes were zero and were excluded from the 6,500 procedures that were used for comparison with the Maryland Medicaid fee schedule. Many procedure codes in Maryland's Medicaid fee schedule do not exist in the Medicare fee schedule. Some local codes are not nationally recognised. One example that can be cited is the current procedural terminology (CPT) codes. The analysis indicated that the reimbursement rates of Maryland Medicaid 2001 were, on average, about 36\% of 2001 Medicare rates for procedures that matched. There are several reasons for this low level of reimbursement rates as compared to Medicare rates. As mentioned in the introduction, prior to July 2002, Maryland Medicaid physician fees had not increased for over a decade because most additional funds were allocated either to expanding the Medicaid-covered population, or to fee increases for other Medicaid-covered services. Another reason for this low level of reimbursement is that the majority of Medicaid patients are indigent individuals who have historically (prior to the enactment of Medicaid in 1965) received charity care from physicians. Therefore, Medicaid physician fees in most states have always been much lower than private or Medicare fees.

\subsection{Comparison with the reimbursement rates of other states}

To offer an alternative point of comparison, payments to physicians made in other states by Medicaid programmes were examined. This analysis has the advantage that the populations of Medicaid programmes in all the states are similar; that is, all of them comprise mostly women and children. As such, all Medicaid programmes have defined procedures and reimbursement rates for maternity and immunisation services. However, while the populations and programmes are similar, the states have different approaches to 
establishing fee structures. This section of the article provides information on overall state-by-state Medicaid physician payment rates and the processes used by other states in updating physician fees.

\subsubsection{Independent studies}

There have been three recent independent studies that have surveyed and compared payments made by different states for Medicaid physician services. Two of the three studies demonstrate that the fee structure of Maryland is lower than that of other states. These studies were based on a subset of procedures used by physicians. Some of the procedure codes used in all three studies are high volume procedures and are identical. However, each survey includes its own unique procedures that are not available in the other surveys. Thus, the findings of these studies are not directly comparable to each other or to the analysis of the Medicare fee schedule, which compared every Maryland Medicaid procedure that matched the Medicare fee schedule. These studies are briefly summarised below.

- The National Medicaid fee survey published by the Lewin Group in March 2001 included the 50 states and District of Columbia (Menges, et al., 2001). For this study, physician fees were collected for about 50 procedures. On a weighted-average basis, the rank for Maryland is 39. Neighbouring states' ranks are: Delaware: 10, District of Columbia: 46, Pennsylvania: 43, Virginia: 25, West Virginia: 14, and New York: 51.

- US Academy of Pediatrics conducted a survey in 1998/1999 of Medicaid reimbursement rates. This is available on their website (Medicaid Reimbursement Survey, 1998/1999; 2001). The rates for a subset of procedures and the corresponding numbers of claims made by Maryland for these procedures were used to derive weighted-average payments for each state. Based on the results, Maryland ranked at 47, followed by Washington, DC at 48, New Jersey at 49, and New York at 50 .

- The study published by the Urban Institute showed that, for the selected procedures, Maryland physician fees were 64\% of Medicare fees for the year 1998 (Norton, 1999). Based on these procedures, the average physician fees for Maryland were $12 \%$ above the national Medicaid average.

\subsubsection{Processes for updating fee schedules of medicaid agencies in other states}

A telephone survey was conducted of 10 states (California, Illinois, Maine, Michigan, Missouri, New York, Pennsylvania, Rhode Island, South Carolina, Utah) and Washington, DC, which were identified by the surveys mentioned above as having the lowest fee rankings among the states. Of the states surveyed, eight states indicated that they based physician fees on the Medicare RBRVS. One state does not base fees on the Medicare schedule but uses it as a comparison point when setting physician fees. Seven of the states surveyed indicated that they use some physician procedure codes that do not have a corresponding match in the Medicare RBRVS.

In most of the states surveyed, increases in the fee charged by physicians depend on budget appropriations. Most of the states surveyed noted that fee adjustments were highly dependent on legislative appropriations and not on cost or market influences. Availability 
of funds was most often cited as the basis for adjusting fees for procedures. One state cited cost and another cited volume of service as factors that affect fee increase for procedures. Several states noted disparate increases for specific codes based on provider input. In most of the states, medical consultants set the fees of the physicians.

\section{Adjusting reimbursement rates for services provided by physicians}

\subsection{Targeting of Medicaid fee increase}

In 1997, prior to the implementation of Maryland's Medicaid managed care programme (HealthChoice), Maryland was spending \$269 million in total funds on physician reimbursement. Because of the volume of physician services, even modest increases in reimbursement rates impact the budget significantly.

One of the most significant challenges in addressing fee increases is targeting any new resources to address the most significant issues affecting Medicaid enrollees. A review of the literature indicated that price elasticity of physician participation in the Medicaid programme is in the range of 0.24 to 0.36 . This price elasticity implies that a $10 \%$ increase in physician fees would increase physician participation by 2.5 to $3.6 \%$ (Adams, 1995). Another study concluded that the number of physicians participating in Maine and Michigan Medicaid programmes did not change in response to changes in reimbursement rates that ranged from 10 to 20\% (Coburn, Long and Marquis, 1999). Therefore, a 10 to $20 \%$ increase in fees for all procedures would, most likely, not cause a substantial increase in physician participation in the Maryland Medicaid programme. With limited resources, it was critical to target new funds to areas where they can have a significant impact on enrollees' access to physician services.

Primary care physicians have assumed increased responsibility in the healthcare system, and their participation is vitally important for achieving and maintaining better health status for Medicaid enrollees. They are playing a more complex role in healthcare than ever before. As generalists, they diagnose and manage many common illnesses. They also provide preventive medical services, such as screening for cancer and cardiac risk factors, or updating immunisation records. Primary care physicians also act as case managers for their patients by coordinating the healthcare that they receive from various specialists. Under managed care, primary care physicians not only coordinate the care of their patients, but also act as the agent of the managed care organisation to approve the insurance payment for services provided to the patients. The conflict of interest inherent in acting both as a patient advocate and an agent for the managed care organisation complicates the work of the primary care physicians and demands that they evaluate cost effectiveness of treatments recommended by them without jeopardising the patients' care (Ubokudom, 1997).

As indicated in the previous section, Medicaid enrollees are mostly women and children. Visits to physicians who provide primary care to women and children, such as general practitioners, pediatricians, and obstetricians/gynecologists account for the majority of physician services under the Medicaid programme. Fee-for-service claims data by type of physician specialty for the year 2000 was analysed. Table 2 shows payments for Evaluation and Management procedures (CPT codes 99201-99499) as a percent of total payments for all physicians. As this table shows, evaluation and management procedures comprise a significant portion of payments to many specialists. 
Following fee increase, an estimated $33 \%$ of additional funds would flow to primary care physicians ${ }^{4}$ and $67 \%$ would flow to physician specialists.

Table 2 Year 2000 fee-for-service payments for evaluation and management procedures as percent of total payments

\begin{tabular}{|c|c|c|c|c|}
\hline Providers'Specialty & $\begin{array}{l}\text { Payment for E \& } \\
M \text { Procedures }\end{array}$ & $\begin{array}{l}\text { Total Medicaid } \\
\text { FFS payments }\end{array}$ & $\begin{array}{l}\text { E\&M as } \\
\% \text { of Total } \\
\text { Medicaid } \\
\text { Revenues }\end{array}$ & $\begin{array}{c}\text { Specialty } \\
\text { Share of Total } \\
(\%)\end{array}$ \\
\hline Primary care physicians & $\$ 4,702,390$ & $\$ 8,578,688$ & 55 & 33 \\
\hline $\begin{array}{l}\text { All other physician } \\
\text { specialties }\end{array}$ & $\$ 2,010,005$ & $\$ 17,669,530$ & 11 & 67 \\
\hline Total & $\$ 6,712,395$ & $\$ 26,248,218$ & 26 & 100 \\
\hline
\end{tabular}

Note: $\mathrm{E}$ and $\mathrm{M}$ stands for evaluation and management procedures, which correspond to CPT Codes 99201-99499. FFS stands for fee-for-service (non-managed care) programme

\subsection{Increasing Medicaid reimbursement rates}

Based on the preceding analysis, Maryland Medicaid targeted the July 2002 increase in reimbursement rates to evaluation and management procedures. These procedures are usually office visits provided by either a primary care physician or a specialist. Primary care physicians, such as pediatricians and general practitioners, provide high proportions of evaluation and management services. Specialists, including hospital-based physicians, also provide evaluation and management services and therefore also benefit from the higher reimbursement rates.

As indicated in Section 3, physicians incur three types of expenses to deliver patient services. The first component is the physicians' 'work' involved in performing each procedure. The second component is the expense for medical supplies, office rent, and other costs that physicians incur to deliver a service or perform a procedure. The third component is the malpractice insurance cost that physicians must pay. The malpractice insurance expense for each procedure depends on the risks involved with delivering that procedure.

An estimate was made of the different components of the expenses incurred by the physicians, using the Resource Based Relative Value Scale (RBRVS) used by the Centers for Medicare and Medicaid Services (formerly the Health care Financing Administration) to develop reimbursement rates for the Medicare programme. The RBRVS methodology provides for a separate estimate of the cost associated with the three distinct components: work; practice expense and malpractice expense.

Medicaid fees were adjusted by increasing the reimbursement rates for evaluation and management procedures (CPT codes 99201-99499) to match the sum of practice and malpractice expense components of fees for each of these procedures as estimated using the RBRVS methodology. Subsequently, reimbursement rates for these procedures were adjusted in an iterative process until the projected increase in expenditures for these procedures equaled the funds that were allocated to increasing physician fees.

Since July 2002, Maryland Medicaid has reimbursed physicians for the full practice and malpractice expense components for evaluation and management procedures and has 
covered, within state resources, a portion of the work component. With this adjustment in fees, Maryland Medicaid increased the reimbursement rates for evaluation and management procedures from an average of 33\% to an average of $80 \%$ of Medicare fees in 2002, and an average of 79\% of Medicare fees for 2003. Since July 2002, Maryland Medicaid physician fees have not increased.

\subsection{Implication of the fee increase for payments to MCOs}

Capitation rates for MCOs participating in the HealthChoice programme were built on the historic expenditures of the Medicaid fee-for-service programme. Maryland regulations require that the state increase $\mathrm{MCO}$ capitation rates to compensate them for any increase in Medicaid fee-for-service payment rates because this would raise the 'base' on which MCO rates are built. The MCO capitation rates were increased in July 2002 to reflect the cost of the physician fee adjustment. To ensure that the MCOs use these funds to raise physician fees to maintain an adequate number of physicians, Maryland Medicaid is using the following method to monitor MCOs' compliance with the fee increase:

- MCOs are required to pay their network physicians at least $100 \%$ of the new Medicaid fee schedule for the approximately 140 evaluation and management procedure codes targeted by the increase

- If an MCO wants to use the new revenues to increase other physician fees rather than pay the new fee schedule for the targeted services, it must request a waiver from Maryland Medicaid. The Medicaid programme will review and approve a waiver if an MCO demonstrates that the total dollar value of the difference between the MCO's old fees for the targeted codes and the new fee schedule is passed on to physicians.

To date, all of the participating MCOs have decided to pay at least $100 \%$ of the new fee schedule for the evaluation and management codes.

\subsection{Analysis of Maryland Medicaid fees after the rate increase}

After the rate increase, the Maryland Medicaid's payment rates were compared with the Medicare programme's 2002 and 2003 average payments in Maryland. The analysis indicated that Maryland's Medicaid reimbursement rates before the July 2002 fee increase were, on average, about $41 \%$ of 2002 Medicare rates for procedures that matched. In 2002, Medicare physician fees decreased by 5.4\% compared to 2001 . After the increase in Medicaid fees for evaluation and management procedures in July 2002, Maryland Medicaid's overall physician reimbursement rates were, on average, about $62 \%$ of 2002 Medicare rates. They currently stand at about $61 \%$ of Medicare rates for 2003.

However, there is a wide variation in the fees for individual procedures compared to Medicare fees. Fees for some procedures are much lower than Medicare fees, while fees for other procedures are close to Medicare fees. As discussed earlier, reimbursement rates for the 140 evaluation and management procedures targeted by the additional funding increased from an average of $33 \%$ to an average of $80 \%$ of Medicare fees for 2002, and an average of 79\% of Medicare fees for 2003. However, Maryland Medicaid fees for other procedures that match Medicare fees (excluding evaluation and management procedures, radiology and laboratory procedures, and procedures with zero 
Medicare fee) were on average 37\% of Medicare fees for 2002, and 36\% of Medicare fees for 2003.

\subsubsection{Specific physician rate comparisons}

Like Maryland, the neighbouring states have their own Medicaid fee schedules. A review of literature indicates that most states, including Maryland, had previously used different relative value studies as benchmarks for setting their physician fees. The relative value studies were precursors to the Medicare Resource Based Relative Value Scale method.

Table 3 Fees for high volume evaluation and management procedures

\begin{tabular}{|c|c|c|c|c|c|c|c|c|c|}
\hline $\begin{array}{l}\text { CPT } \\
\text { Code }\end{array}$ & Description & $D C^{a}$ & $V A^{b}$ & $P A^{b}$ & $D E^{b}$ & $\begin{array}{l}W . \\
V A^{b}\end{array}$ & $M D^{c}$ & $\begin{array}{l}\text { Medi } \\
\text { Care }^{d}\end{array}$ & $\begin{array}{l}\text { Min } \\
\text { Private } \\
\text { fee }^{e}\end{array}$ \\
\hline 99201 & New Patient, Office Visit & 25 & 29 & 25 & 38 & 35 & 29 & 36 & 56 \\
\hline 99202 & New Patient, expanded office visit & 30 & 45 & 20 & 59 & 55 & 51 & 65 & 74 \\
\hline 99203 & New Patient, low complexity & 30 & 63 & 20 & 83 & 77 & 77 & 96 & 97 \\
\hline 99204 & New Patient, intermediate complexity & 35 & 91 & 20 & 120 & 110 & 109 & 136 & 142 \\
\hline 99205 & New Patient, high complexity & 59 & 114 & 30 & 149 & 136 & 139 & 174 & 182 \\
\hline 99211 & Established Patient, Office Visit & 15 & 14 & 20 & 19 & 19 & 17 & 21 & 29 \\
\hline 99212 & $\begin{array}{l}\text { Establish. Patient, expanded office } \\
\text { visit }\end{array}$ & 18 & 24 & 20 & 32 & 29 & 30 & 38 & 45 \\
\hline 99213 & Established Patient, low complexity & 18 & 34 & 20 & 44 & 39 & 42 & 53 & 62 \\
\hline 99214 & $\begin{array}{l}\text { Establish. Patient, intermediate } \\
\text { complexity }\end{array}$ & 30 & 52 & 20 & 68 & 61 & 66 & 83 & 92 \\
\hline 99215 & Established Patient, high complexity & 41 & 77 & 20 & 101 & 87 & 97 & 121 & 136 \\
\hline 99242 & Office Visit, straightforward decision & 33 & 65 & 30 & 85 & 77 & 73 & 91 & 134 \\
\hline 99243 & Office Visit, low complexity & 43 & 83 & 30 & 109 & 97 & 97 & 120 & 161 \\
\hline 99244 & Office Visit, intermediate complexity & 60 & 115 & 49 & 151 & 134 & 137 & 171 & 207 \\
\hline 99245 & Office Visit, high complexity & 65 & 149 & 49 & 196 & 168 & 178 & 222 & 271 \\
\hline
\end{tabular}

Note: ${ }^{a}$ American Academy of Pediatrics Survey of Medicaid Reimbursement (1998/1999)

${ }^{\mathrm{b}}$ American Academy of Pediatrics Survey of Medicaid Reimbursement (2001)

${ }^{c}$ Fee schedule as of July 2002

${ }^{\mathrm{d}}$ Medicare Fee schedule for March through December 2003

e2003 Physicians Fee \& Coding Guide, MAG Mutual Healthcare Consultants

A comparison was made of Maryland Medicaid fees for some of the high volume procedures with the Medicaid fees of neighbouring states and with the corresponding Medicare fees. The result of a survey conducted by the American Academy of Pediatrics $(1998 / 1999)$ of Medicaid reimbursement rates across the country has already been discussed. The American Academy of Pediatrics conducted a similar survey in 2001. 
Based on the 2001 survey data and Maryland's new fees for evaluation and management procedures, Maryland ranks at 13. Ranks of neighbouring states are: Delaware: 6, District of Columbia: 47, Pennsylvania: 46, Virginia: 15, and West Virginia: 11.

The American Academy of Pediatrics survey results for high volume evaluation and management procedures for the neighbouring states are shown in Table 3, along with the corresponding Maryland Medicaid rates and 2003 Medicare fees for each listed procedure. The last column of Table 3 shows the minimum fee range for private, non-Medicare charges. It is important to note that fee charges are not the same as the payment received as reimbursement from insurance companies or private pay patients, but rather, what physicians would like to receive for their services.

\subsection{Physician participation in Maryland Medicaid programme}

The data of physicians claims pertaining to the year before and year after fee increase were analysed for a number of physicians who had either partial or full participation in the Medicaid programme. Physicians were considered full participants in the Medicaid programme if they had visits with at least 50 patients during the year. Table 4 shows percentage changes in numbers of primary care physicians in fee-for-service (FFS), MCO networks, and total Medicaid programme.

Table 4 Percent increase in number of primary care physicians after the fee increase

\begin{tabular}{lccc}
\hline & $F F S$ & MCO networks & Total Medicaid \% \\
\hline Partial participation & 7.4 & 0.1 & 5.1 \\
Full participation & $10.1 \%$ & 0.3 & 2.0 \\
\hline
\end{tabular}

Following the increase in reimbursement rates, physicians substantially increased their participation in the fee-for-service programme. However, prior to the fee increase, many MCOs had sufficient numbers of primary care physicians in their networks. Therefore, they did not substantially increase the number of their contracting primary care physicians. This led to a modest overall increase in the number of primary care physicians who participate in the Medicaid programme.

Table 5 shows percentage changes in numbers of physicians of all specialties who participate in fee-for-service (FFS), MCO networks, and total Medicaid programme. As the data in Table 5 indicate, there were significant increases in participation of physicians in fee-for-service, MCO networks, and total Medicaid programme.

Table 5 Percent increase in number of physicians (all specialties) after the fee increase

\begin{tabular}{lccc}
\hline & FFS & MCO networks & Total Medicaid \\
\hline Partial participation & 7.3 & 5.3 & 7.7 \\
Full participation & 8.6 & 6.6 & 7.1 \\
\hline
\end{tabular}




\section{$5 \quad$ Future fee increases}

The additional funds provided in 2002 were used to significantly increase reimbursement rates for evaluation and management procedure codes commonly used for office visits by both primary care physicians and specialists. However, as indicated in Section 4.4, the reimbursement rates of Maryland Medicaid for non-evaluation and management codes remain well below the rates paid by Medicare. Therefore, the state could allocate any additional funds that become available to increasing reimbursement rates for these procedures and procedures that do not have a corresponding Medicare fee. Once reimbursement rates for all procedures performed by physicians are raised to a certain level to be competitive with Medicare, or are adjusted to correspond to Usual, Customary, and Reasonable (UCR) fees, additional funds could be targeted to maintain their parity with Medicare and UCR fees.

Table 6 compares the current Maryland Medicaid rates with Medicare rates in 2003, rates paid by other states, and the minimum of private charges for a sample of common, non-evaluation and management procedures. As the data in Table 6 show, the reimbursement rates of Maryland Medicaid are very low for some of these procedure codes.

Table 6 Fees for high volume, non-evaluation and management procedures

\begin{tabular}{|c|c|c|c|c|c|c|c|c|c|}
\hline $\begin{array}{l}\text { CPT } \\
\text { Code } \\
\end{array}$ & Description & $D C^{a}$ & $V A^{b}$ & $P A^{b}$ & $D E^{b}$ & W. $V A^{b}$ & $M D^{c}$ & $\begin{array}{l}\text { Medi } \\
\text { care }^{d}\end{array}$ & $\begin{array}{c}\text { Min } \\
\text { private } \\
\text { fee }^{e}(\%)\end{array}$ \\
\hline 31500 & $\begin{array}{l}\text { Intubation Endotracheal } \\
\text { Emergency }\end{array}$ & 66 & 88 & 72 & 115 & 85 & 31 & 118 & 258 \\
\hline 31622 & Bronchoscopy & 117 & 162 & 166 & 212 & 171 & 113 & 243 & 662 \\
\hline 32020 & Insertion of Chest Tube & 130 & 169 & 211 & 220 & 160 & 42 & 217 & 555 \\
\hline 36489 & $\begin{array}{l}\text { Insertion of Catheter, } \\
\text { Vein }\end{array}$ & 47 & 95 & 88 & 125 & 132 & 36 & 256 & NA \\
\hline 36620 & $\begin{array}{l}\text { Insertion of Catheter, } \\
\text { Artery }\end{array}$ & 36 & 45 & 58 & 58 & 40 & 21 & 54 & 190 \\
\hline 43239 & $\begin{array}{l}\text { Upper GI Endoscopy, } \\
\text { Biopsy }\end{array}$ & 123 & 174 & 212 & 228 & 187 & 234 & 352 & 698 \\
\hline 44950 & Appendectomy & 267 & 381 & 302 & 496 & 398 & 206 & 578 & 1,375 \\
\hline 62270 & $\begin{array}{l}\text { Spinal Puncture, } \\
\text { Lumbar, Diagnostic }\end{array}$ & 35 & 88 & 42 & 116 & 131 & 18 & 191 & 184 \\
\hline 69436 & $\begin{array}{l}\text { Tympanostomy, General } \\
\text { Anesthesia }\end{array}$ & 81 & 108 & 99 & 141 & 107 & 83 & 157 & 497 \\
\hline 92551 & $\begin{array}{l}\text { Pure Tone Hearing Test, } \\
\text { Air Only }\end{array}$ & 8 & 9 & 8 & 17 & 14 & 4 & NA & 28 \\
\hline
\end{tabular}


Table 6 Fees for high volume, non-evaluation and management procedures (Continued)

\begin{tabular}{|c|c|c|c|c|c|c|c|c|c|}
\hline $\begin{array}{l}\text { CPT } \\
\text { Code }\end{array}$ & Description & $D C^{a}$ & $V A^{b}$ & $P A^{b}$ & $D E^{b}$ & W. $V A^{b}$ & $M D^{c}$ & $\begin{array}{l}\text { Medi } \\
\text { care }^{d}\end{array}$ & $\begin{array}{c}\text { Min } \\
\text { private } \\
\text { fee }(\%)\end{array}$ \\
\hline 92567 & $\begin{array}{c}\text { Tympanometry, Hearing } \\
\text { Evaluation }\end{array}$ & 6 & 15 & 12 & 20 & 16 & 5 & 22 & 36 \\
\hline 93303 & $\begin{array}{l}\text { Transthoracic } \\
\text { Echocardiography }\end{array}$ & 117 & 163 & NA & 214 & 163 & 38 & 225 & 495 \\
\hline 93307 & $\begin{array}{l}\text { Echocardiography, Real } \\
\text { Time }\end{array}$ & 113 & 152 & 158 & 199 & 150 & 34 & 205 & 427 \\
\hline 93320 & $\begin{array}{l}\text { Doppler } \\
\text { Echocardiography }\end{array}$ & 50 & 66 & 107 & 87 & 66 & 52 & 90 & 310 \\
\hline 93510 & $\begin{array}{l}\text { Left Heart } \\
\text { Catheterization }\end{array}$ & 108 & 1,219 & 188 & 1,596 & 1,252 & 80 & 1,731 & NA \\
\hline 94010 & $\begin{array}{l}\text { Spirometry: Breathing } \\
\text { Capacity Test }\end{array}$ & 16 & 21 & 15 & 28 & 18 & 13 & 42 & 69 \\
\hline
\end{tabular}

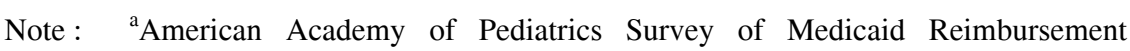
(1998/1999)

${ }^{\mathrm{b}}$ American Academy of Pediatrics Survey of Medicaid Reimbursement (2001)

${ }^{\mathrm{c}}$ Fee schedule as of July 2002

${ }^{\mathrm{d}}$ Medicare Fee schedule for March through December 2003

e 2003 Physicians Fee \& Coding Guide, MAG Mutual Healthcare Consultants

\section{Conclusion}

The aforementioned relationship between physician participation and level of reimbursement rates and analysis presented in Section 4.5 indicates that the substantial increase in Maryland Medicaid physician fees in July 2002 has led to increased participation of physicians in the Medicaid programme, which would enhance the access of Medicaid enrollees to them.

The latest Medicaid physician fee increase that was implemented in July 2002 targeted evaluation and management procedures, which are extensively used by primary care physicians, as well as specialists. Unlike specialists who attract patients from a wide geographical area, primary care physicians attract most of their patients from the area immediately surrounding their practice location. This is especially true for primary care physicians who treat Medicaid beneficiaries. Therefore, Medicaid enrollees are likely to constitute a large portion of patients of primary care physicians who establish their practice in lower income areas and poorer neighbourhoods. A survey conducted for California Medicaid (Medi-Cal) indicated that $25 \%$ of primary care physicians provided $80 \%$ of the primary care visits to Medi-Cal patients (Bindman et al., 2003). Analysis of Maryland Medicaid claims data indicates similar results: $21 \%$ of participating physicians provided $86 \%$ of total number of claims. In lower-income neighbourhoods with large indigent populations, Medicaid enrollees could constitute a major percentage of all patients of a primary care physician. Therefore, one result of the last Maryland Medicaid fee increase is that primary care physicians who serve Maryland Medicaid enrollees 
would receive a more adequate compensation. Consequently, these physicians would have sufficient financial incentives to continue with their practices in lower-income areas and poorer neighbourhoods. Similarly, new physicians who consider establishing their practices in the low-income neighbourhoods of Maryland would have financial incentives to do so. This would, in turn, lead to increased access to primary healthcare services for Maryland Medicaid enrollees.

\section{Acknowledgements}

Many individuals at the Maryland Department of Health and Mental Hygiene and the Center for Health Program Development and Management have participated in the discussions about increasing Medicaid reimbursement rates for physicians who participate in the Medicaid programme. These individuals have either directly or indirectly contributed to this article. While it is not possible to acknowledge the contribution of each one of these individuals, John Folkemer and Alice Burton deserve special thanks. Yue Ying (Anna) Lau provided expert SAS programming and data processing support for this project. Sanya Rusticelli must be thanked for her editorial comments.

\section{References}

Adams, E.K. (2001) 'Factors affecting physician provision of preventive care to medicaid children', Health Care Financing Review, Vol. 22, No. 4, pp.9-26.

Adams, E.K. (1995) 'Effects of increased medicaid fees on physician participation and enrollee service utilization in Tennessee, 1985-1988', Inquiry, Vol. 31, No. 2, pp.173-187.

Baker, L. and Royalty, A.B. (2000) 'Medicaid policy, physician behavior, and health care for the low-income population', Journal of Human Resources, Vol. 35, No. 3, pp.480-502.

Berman, S., Dolins, J., Tang, S. and Yudkowsky, B. (2002) 'Factors that influence the willingness of private primary care pediatricians to accept more medicaid patients', Pediatrics, Vol. 110, No. 2, pp.239-248.

Bindman, A.B., Yoon, J., Grumback, K. and Streett, L. (2003) Physician Participation in Medi-Cal, 2001, MediCal Policy Institute, http://www.chcf.org/documents/medical/ Medi-CalPhysParticipation2001.pdf.

Coburn, A.F., Long, S.H., and Marquis, M.S. (1999), 'Effects of changing medicaid fees on physician participation and enrollee access', Inquiry, Vol. 36, No. 3, pp.265-279.

Kaiser Family Foundation (2003), 'State health facts online', Calculated Based on Physicians Professional Data as of 2001, Copyright American Medical Association, 2002 and 2001 Civilian Population Data: Annual Population Estimates by State, July 1, 2001 Population, U.S. Census Bureau, http://statehealthfacts.kff.org.

'Medicaid Reimbursement Survey' (1998/1999, 2001), American Academy of Pediatrics, http://www.aap.org/research/medreimintro.htm.

Menges, J., Park, C., Babcock, J., Chimento, L., Haught, R. and Ho, S. (2001) Comparing Physician and Dentist fees Among Medicaid Programs, MediCal Policy Institute, The Lewin Group, http://www.chcf.org/documents/medical/ComparingPhysicianAndDentistFees.pdf.

Norton, S. (1999) 'Recent trends in medicaid physician fees, 1993-1998', The Urban Institute, http://www.urban.org/UploadedPDF/discussion99-12.pdf 
Tucker III, J. L. (2002) 'Factors influencing physician participation in medicaid in the USA', International Journal of Social Economics, Vol. 29, No. 9, pp.753-762.

Ubokudom, S.E. (1997), Physician Participation in Medicaid Managed Care, Garland Publishing, Inc. New York.

\section{Notes}

1 Maryland's Health Services Cost Review Commission determines payment rates to hospitals, and all payers (Medicaid, Medicare, commercial insurance companies, etc.) pay the same rate to each hospital.

2 Section 1396a(30)(A) of the Medicaid act. The Balanced Budget Act of 1997 eliminated this requirement.

3 Centers for Medicare and Medicaid Services (CMS) and Medicare Payment Advisory Commission (MedPac) publications. Section 601 of the Medicare Prescription Drug, Improvement and Modernization Act (MPDIMA) of 2003, Public Law 108-173, specified that the annual update of conversion factors for 2004 and 2005 would not be less than $1.5 \%$.

4 Primary care physicians are defined as physicians with Family Practice, General Practice, Internal Medicine, Obstetrics/Gynecology, or Pediatrics specialties. 